\title{
The utilitarian case against the universal basic income
}

\author{
Marko Kovic*
}

May 2020

\begin{abstract}
The universal basic income (UBI) is morally desirable because it makes peoples' lives better: If a UBI were to be implemented, average and total welfare in the population would significantly increase. However, I argue that a non-universal basic income that is adjusted for people's prior income and wealth (and which therefore takes into account the diminishing marginal utility of money on individual welfare) is more effective than the UBI at maximizing welfare in a population. If we sincerely care about the utilitarian goal of the UBI, then nonuniversal basic income schemes that are better at achieving that goal should be considered both in theory as well as in practice.
\end{abstract}

*markokovic@gmail.com 


\section{The moral foundation of the universal basic income}

Why should there be a universal basic income (UBI)? There are different answers to this question, but they ultimately converge into a single elegant moral proposition: All else being equal, a UBI improves people's lives.

This moral claim is quite explicit in most, if not all justifications of the UBI. When the UBI is justified on the grounds that such an income has a freedom- and equality-maximizing function that allows citizens to live their lives how they see fit [1, 2, 3, 4] — this can be called the liberal argument — , then people's lives are improved insofar as they gain the freedom to pursue their goals and tastes. When the UBI is justified with regards to its concrete, tangible impact on people's development and flourishing [5] - this can be called the practical argument —, then people's lives are improved insofar as their immediate wellbeing and their overall life prospects improve 1. The practical and the liberal arguments ultimately overlap and coverge, since practical freedom springs from the ability to make life decisions without the pressures and distortions imposed by severe material constraints.

Regardless of whether one prefers the more theoretical argument of freedom-maximization or the more practical argument of improved outlook in different domains of life, the justification for the UBI is ultimately consequentialist in nature: The UBI is morally desirable because implementing it has certain desirable consequences. More precisely, the moral underpinnings of the UBI make it a utilitarian project: The UBI is morally desirable insofar as it increases total and average welfare in the population ${ }^{2}$. Of course, this is somewhat of a trivial truism. I imagine that all proponents of the UBI find it morally desirable primarily and precisely because it would make people's lives better 3 .

\footnotetext{
${ }^{1}$ For example, a UBI would in all likelihood have positive effects on health and on educational attainment [6, 7, 8, 9], and it could mitigate (some of) the psychological duress that results from and is intensified by poverty [9]. In addition, the UBI also improves people's lives in the more plainly obvious way of making (some of) the basic goods necessary in daily life, such as food and shelter and mobility, more readily accessible.

${ }^{2}$ I emphasize that the moral goal is to increase both average and total welfare because doing so avoids certain problems related to population ethics that can arise when only total welfare, the main consideration in traditional utilitarianism [10], is pursued. The most notable of these problems are the repugnant conclusion [11] and the nonidentity problem 12 .

${ }^{3}$ For the sake of simplicity and brevity, I refrain from discussing fringe cases of individuals with "special tastes" such as psychopaths, sadists or masochists who derive pleasure from their own or other people's suffering and whose lives would accordingly somewhat worsen if a UBI were to be implemented.
} 
If the UBI were to move from theory to practice and be implemented on a large scale, it would almost certainly have the desired moral impact: Any kind of nontrivial real-world UBI would lead to a significant increase in average and total welfare and therefore to an improvement of people's lives. There is, in my view, little doubt about this. But there is an additional question that needs to be addressed. If the UBI's moral goal is to improve people's lives, is it actually an optimal or even an acceptably good mechanism for doing so? The UBI is better than the status quo, but could there be a different kind of basic income scheme that is morally preferable to the UBI because it is more effective than the UBI in terms of increasing welfare? This question has received little attention so far. A notable exception is Pettit's [13] comparison of the liberal, the republican and the utilitarian justifications of the UBI in which he concludes that utilitarianism fails to adequately explain why the UBI should exist. But Pettit has it backwards: The question is not whether utilitarianism can justify the UBI, but whether the UBI delivers on its utilitarian promises.

In this article, I argue that it does not: The UBI goes some way towards achieving its utilitarian goal (instituting a UBI is always preferable to the status quo), but due to the universality constraint, it is neither theoretically nor practically optimal for achieving the goal of improving people's lives. More specifically, I argue that the UBI is morally inferior to some forms of non-universal basic income that take into account the diminishing marginal utility of money and allocate the basic income depending on one's prior material conditions (income and wealth).

I develop this argument by first laying out its premises in section 2. Then, in section 3, I present the rather simple core argument of this article. In section 4. I discuss some of the most important potential objections ot my argument. I end the article with some concluding remarks in section 5.

\section{Premises of the argument}

The argument I present rests on two premises. First, I believe that there is a positive relationship between money and individual welfare. Second, I believe that the positive relationship between money and individual welfare is not linear but that money has a diminishing marginal utility. Both of these premises are not overly controversial (I would expect most proponents of the UBI to agree with them en passant), but it is worth spelling them out so as to make the overall argument of this paper as clear as possible. 


\subsection{Premise 1: Money increases individual welfare}

The first premise of my argument is that money increases individual welfare, and an increase in individual welfare results in an aggregate increase of both the total and the average welfare in a population.

I use the term "welfare" in the utilitarian sense of presence of happiness or pleasure and the absence of suffering or pain. For the sake of simplicity, I assume that there is a symmetry between happiness and suffering, meaning that an increase in a certain quantity of happiness has the same positive impact on welfare as a reduction of an equivalent quantity of suffering. One could object to this type of quantification on negative utilitarian grounds but even if there is a moral asymmetry between happiness and suffering, the impact of money can still be assumed to be manifest in a net increase in individual welfare, be it through less suffering (which in this case would be preferable) or through more happiness (which would still be good under the assumption of asymmeetry).

Money has the instrumental property of allowing one to achieve one's goals, whatever those may be. Having (more) money therefore equates to having the means to reduce one's suffering and increase one's happiness in a myriad of ways. For example, having a sufficient amount of money allows one to afford the basic goods of daily life, such as a place to live, clothing, food, healthcare, education, and mobility. Money also allows one to pursue more subjectively morally desirable goals and interests that bring one happiness. Person A might find happiness in starting a family, person B in doing more pro bono work, and person $\mathrm{C}$ in pursuing the hobby of woodworking.

This premise verges on the trivial, and it also underlies any kind of argument in favor of a UBI (A UBI is good because the money allocated through the UBI increases people's welfare.). Of course, money is not the only means for increasing welfare (some suffering cannot be alleviated by money alone, and some happiness cannot be "bought"), but under real-world conditions, money is conducive to greater welfare.

\subsection{Premise 2: Money has a diminishing marginal util- ity}

The second premise of my argument is that money has a diminishing marginal utility in terms of welfare. More money means greater welfare, but the more money a person already has, the smaller the additional positive impact of

\footnotetext{
${ }^{4}$ Karl Popper was the first to argue that there is an asymmetry between happiness and suffering and that reducing suffering is more important than increasing happiness [14].
} 
additional money will be. To elaborate on this premise, let us consider the schematic representations in Figure 1.

Figure 1: Four schematic models of the marginal benefits of money on welfare.
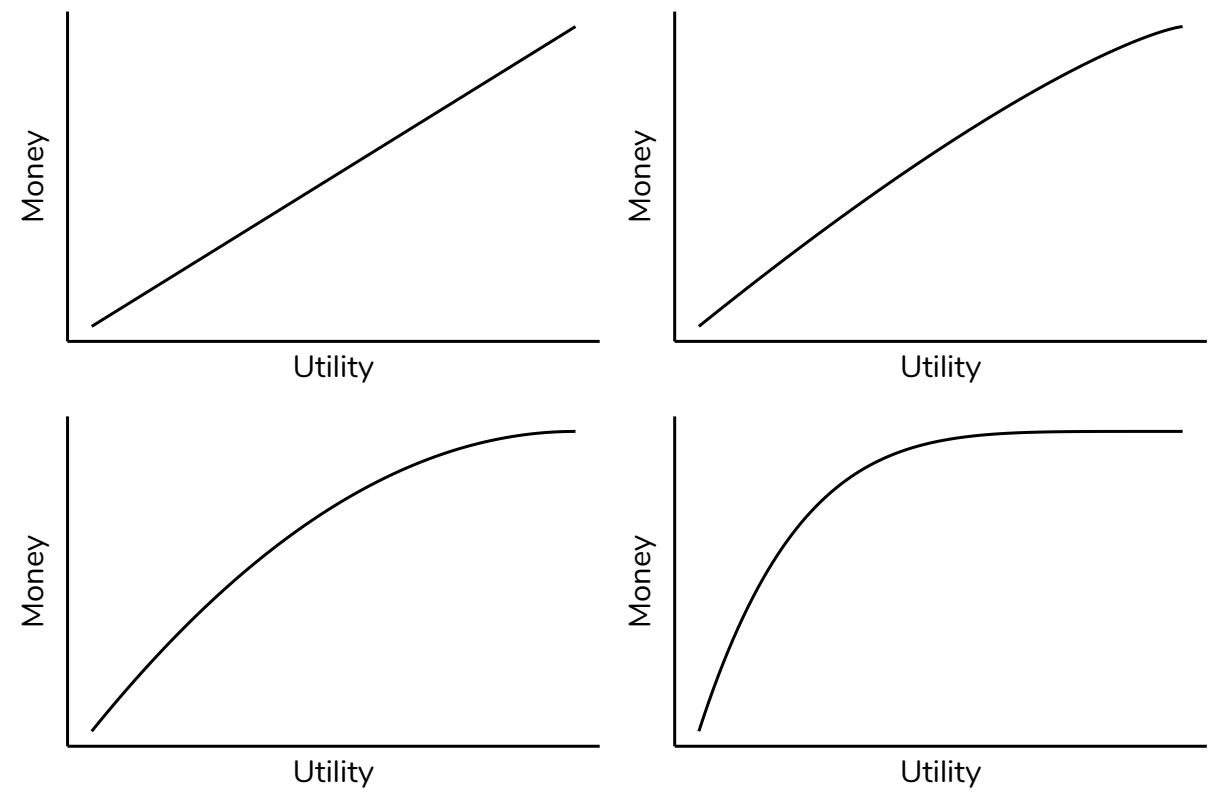

The argument I present in this article only holds if the relationship between money and welfare does not take the steadily linear form of the top left chart. If the utility of money is even only very slightly diminishing (the top right chart depicts what that could look like), then the utilitarian argument against the UBI holds. More severely diminishing marginal utility of money (that looks like something in the bottom left chart) or even a marginal utility that is approaching zero (top right chart) is empirically conceivable but not required for the overall argument.

But why should the marginal utility of money for individual welfare be diminishing? After all, the objective value of money is in no way contingent the quantity of money owned. If someone were to gift you $\$ 500$, you could buy exactly the same products and services with those $\$ 500$ regardless of how much money you happened to have had before the gift. The price of things is fixed and not affected by how much money one has at her or his disposal.

It is true that more money allows one to purchase more (or more expensive) goods and services, but the objective and subjective benefit one derives from more or more expensive things does not rise at the same rate indefinitely. If one is hungry, a loaf of bread has a very high utility. A second 
loaf of bread might still be beneficial, but after the first loaf, one probably is not as hungry anymore. The same goes for money: A low-income person will derive more relative use from the $\$ 500$ gift than a high-income person because the $\$ 500$ allow the low-income person to purchase some of the goods and services and enjoy some of the freedoms that the high-income person already has and enjoys. A given sum of money will have a greater positive impact on one's life if one is living in more dire material conditions.

None of this is new, of course. The logic of diminishing marginal utility has been described at least as far back as the $19^{\text {th }}$ century [15]. Measurements of the correlation between material prosperity and happiness and well-being [16] and between material prosperity and subjective life evaluation and satisfaction 17 tend to show something akin to a diminishing marginal utility. Of course, studies that rely on self-reported feelings of well-being and life satisfaction only approximate the utilitarian concept of welfare, so they need to be taken with a grain of salt. But overall, I believe that both theoretical considerations as well as empirical findings support the notion of diminishing marginal utility of money.

\section{The utilitarian challenge to the UBI}

I present the utilitarian case against the UBI through a thought experiment. In the thought experiment, I compare the impact of a fixed amount of money on two fictional people: A waitress who earns $\$ 20000$ annually and an actor who earns $\$ 1000000$ annually. This is a crass difference in incomes, but the contrast is useful for the sake of argument. The a priori welfare derived from their respective monthly income is depicted in Figure 2, The difference in welfare in Figure 2 is not an empirical measurement but just an illustrative depiction of the fact that the waitress is worse off. The actor could be ten times better off than the waitress (as depicted in the figure), or he could only be one and a half times better off than the waitress. The actual size of the difference in the waitress' and the actor's welfare is inconsequential for the argument. What matters is the general setup of the thought experiment given the two premises outlined in section 2.

Now let us assume that the society in which our waitress and our actor live introduces a UBI of $\$ 12000$ annually, paid out in 12 monthly $\$ 1000$ increments. How would the $\$ 1000$ monthly UBI affect welfare levels of our waitress and our actor? The UBI's positive impact is depicted in Figure 3.

A $\$ 1000$ monthly UBI has a positive impact on both the waitress' and the actor's welfare, as dictated by premise 1 . However, the increase in welfare is unequal: The $\$ 1000$ monthly UBI has a considerably larger effect on the 
Figure 2: Initial welfare levels in the thought experiment.

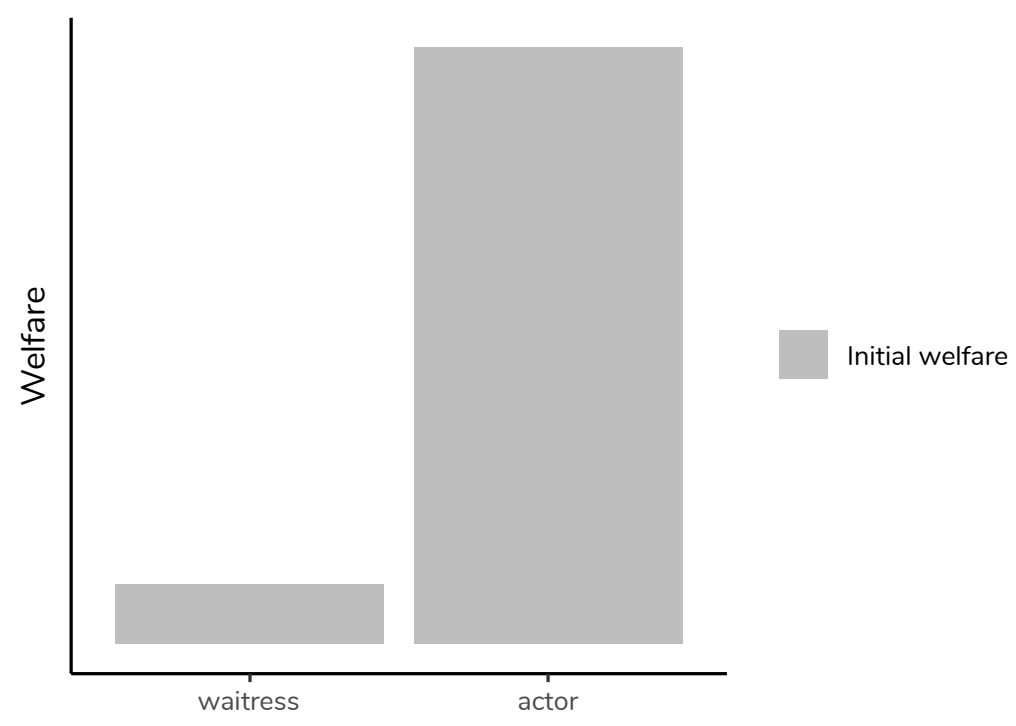

waitress' welfare than on the actor's; this is a consequence of premise 2 , the diminishing marginal utility of money. Since the actor is earning much more money than the waitress, an additional $\$ 1000$ a month will increase his welfare only very slightly. In contrast, a $\$ 1000$ monthly UBI has a much larger effect on the waitress' welfare whose regular income is quite low compared to the actor's income. In and of itself, this observation is not a utilitarian argument against the UBI but rather a demonstration of the UBI's utilitarian merits. The introduction of the UBI has increased both total and average welfare in our sample, making it a morally desirable change compared to the status quo ante. In the real world, adopting the UBI would therefore be morally preferable to not adopting it.

But the the thought experiment gets a little more complicated if allocate the money available under the UBI scheme in a non-universal way. More specifically, let us imagine that the actor receives no money at all and the $\$ 1000$ that he would receive under the UBI go to the waitress instead so that she receives $\$ 2000$ overall. The impact of this change is depicted in Figure 4 .

If the waitress receives an additional $\$ 1000$ on top of the $\$ 1000$ that she would receive under the UBI, her total welfare would increase (as described by premise 1 ), and the utility of the additional $\$ 1000$ would be lower than the marginal utility of the first $\$ 1000$ (as described by premise 2). Crucially, however, the additional $\$ 1000$ that the waitress would receive would have a significantly larger positive effect on her welfare than the $\$ 1000$ which the 
Figure 3: The benefit of a $\$ 1000$ universal basic income.

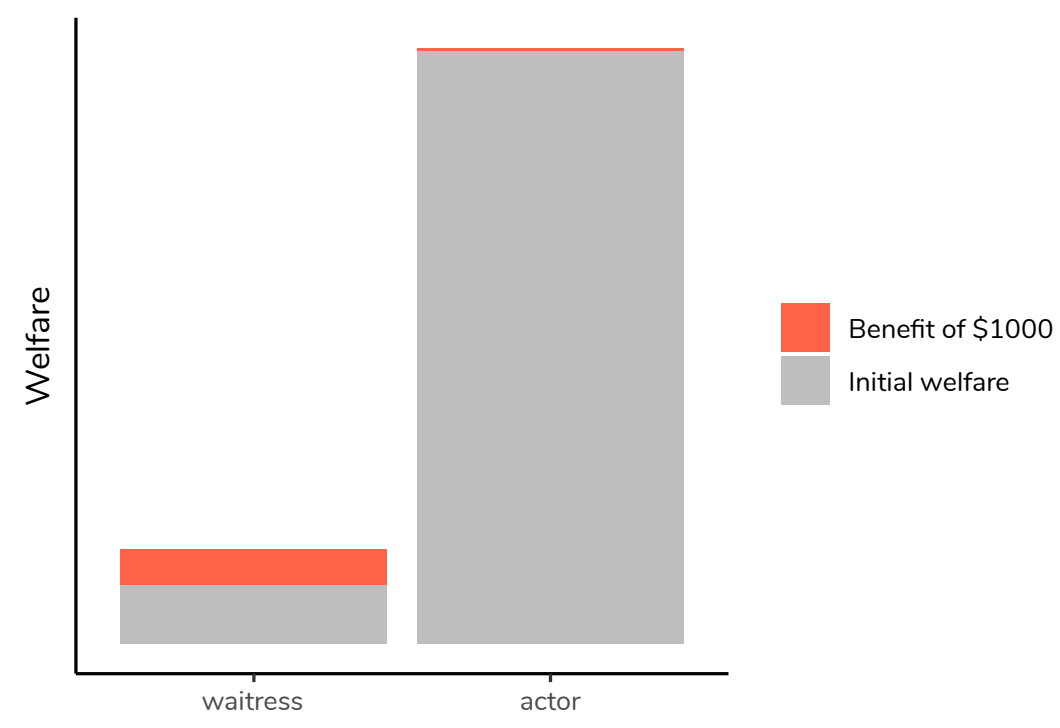

actor would receive under the UBI would have on his welfare. Compared to the UBI arrangement, total and average welfare in our sample are greater when the waitress receives $\$ 2000$ and the actor receives nothing. And therein lies the utilitarian case against the UBI: If the money available under a UBI is allocated in a non-universal manner by adjusting for the diminishing marginal utility of money and thereby maximizing the effectiveness of the money that is allocated, the overall positive impact of the non-universal basic income is categorically greater than the positive impact of the UBI. The moral goal of the UBI can be achieved better through a non-universal basic income.

Does the effect that in this minimal thought experiment also exist in larger, real-world populations? Yes, because the principles of diminishing marginal utility of money are present regardless of how many people with varying degrees of a priori material conditions and welfare derived from those material conditions there are. A UBI will always increase total and average welfare compared to the status quo of no basic income system at all, but the fact that money has diminishing marginal utility means that in a population of any size, an unequal, non-universal distribution of the available money that favors people with lower welfare (meaning people living in worse material conditions) will categorically result in greater increases in average and total welfare compared to the UBI. Given a fixed amount of money available for redistribution under a basic income scheme, a non-universal basic income whose allocation is optimized in this utilitarian manner will 
Figure 4: The relative benefit of a $\$ 1000+\$ 1000$ non-universal basic income.

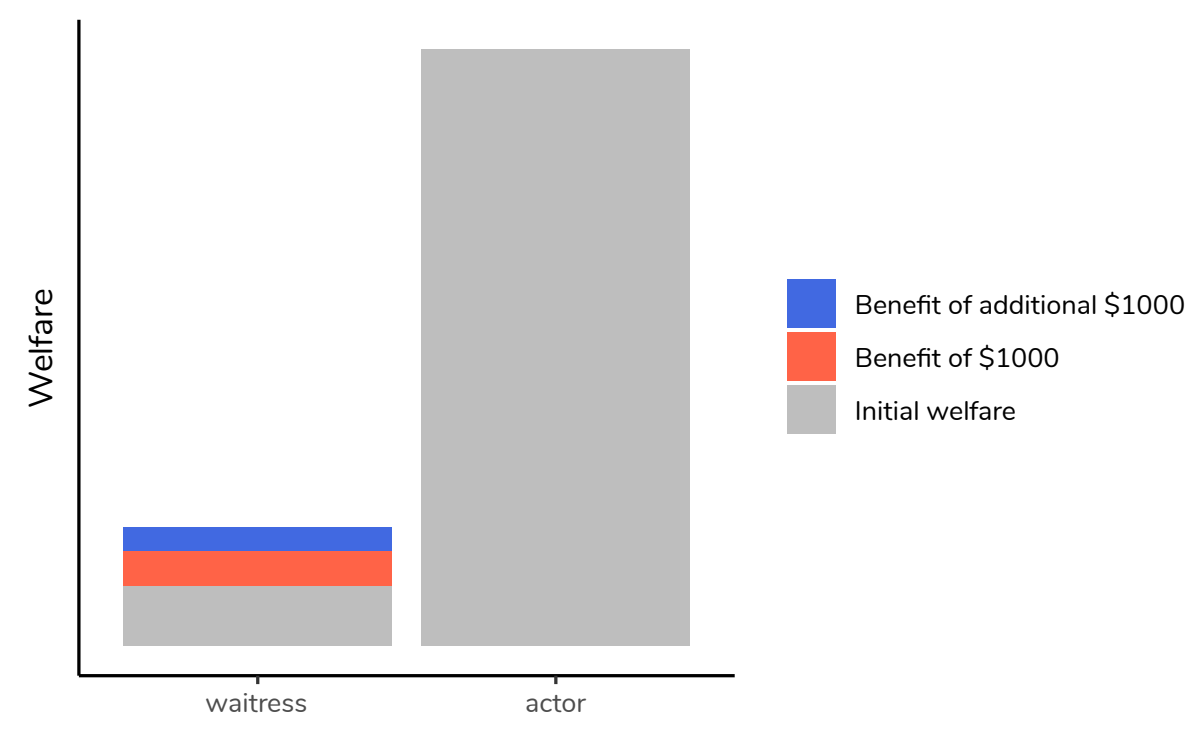

always outperform a UBI.

\subsection{Why negative income tax is not the answer}

The utilitarian case against the UBI might sound like a case for the negative income tax (NIT), a redistributive scheme often discussed in the context of and compared with the UBI [18]. On the face of it, the NIT does indeed seem to outperform the UBI on utilitarian grounds: The fact that money is allocated relative to one's income means that the diminishing marginal utility of money is, at least to some degree, taken into account. In reality, however, the NIT is probably grossly inappropriate on moral grounds and certainly categorically worse than the UBI. To see why, let us return to our thought experiment.

Our starting point is the status quo of no basic income scheme. The waitress and the actor are earning an annual income of $\$ 20000$ and $\$ 1000000$ respectively. The waitress is effectively living paycheck to paycheck, whereas the actor is able to save and invest a considerable part of his income. After ten years, the waitress is still earning the same income (we disregard factors like inflation for the sake of argument), and she was unable to accumulate any kind of wealth; she is still living paycheck to paycheck. The actor on the other hand has considerable cash savings and he has invested around $\$ 3$ million over the years, and his investments are steadily growing in value. 
Because he wants to spend more time with his family and on his hobbies, the actor decides to stop working for a year, meaning that he will have zero income and live off his savings. The same year, a NIT is instituted. For the sake of argument, we assume that the NIT is lagged only by one month: The size of the NIT handed out in January is determined by one's income in December, and so forth.

The NIT benefits both the waitress and the actor since they have low (the waitress) or no income (the actor). On the face of it, this outcome is morally good: Total and average welfare in our sample are greater with the NIT than they would be without it. However, something is morally off: The NIT that the actor receives will be higher than the NIT the waitress receives, since the actor has no income and the waitress is earning around $\$ 1650$ a month. But the actor is, as we know, very wealthy, whereas the actress has no or even negative wealth. Under any reasonable set of assumptions, the actor is much better off thanks to his wealth, yet he would receive more money from the NIT than the actress. This is clearly morally wrong if the goal of the basic income, universal or not, is to actually maximize and not merely marginally increase total and average welfare in the population. The UBI is clearly morally preferable to the NIT because the NIT fails to take prior wealth into account and only relies on income to determine the size of the NIT. The UBI will almost certainly categorically outperform the NIT.

The obervation that wealth is a major distorting factor for any type of NIT dates back to the very beginning of the debate on the NIT in the 1960s [19]. Given that wealth inequality remains a global reality that has, if anything, become even more pronounced in recent decades [20], a simple NIT that fails to take wealth into account is morally unacceptable and inferior not only to the UBI, but potentially also to the status quo of no basic income scheme at all.

\subsection{The cost-cutting trap and minimum welfare}

In the thought experiment presented above, the starting point is a $\$ 1000$ monthly UBI distributed to all people. It is then shown that distributing that total quantity of money in a non-universal way creates greater total and average welfare. However, in light of real-world challenges to implementing a basic income scheme, one could also draw a different conclusion: Why not just save the second $\$ 1000$ altogether and only hand out the first $\$ 1000$ to the waitress? Would that not be the most effective use of money if we are also concerned with limiting the costs of the basic income scheme?

One common criticism of the UBI is its cost, and a non-universal basic income that allocates the same quantity of money as a UBI would be subject 
to the same type of criticism. A non-universal basic income could potentially be made more practically viable by reducing the total quantity of money that is to be allocated. In the context of our thought experiment, that would mean that rather than reallocating the $\$ 1000$ UBI from the actor to the waitress so that she receives a $\$ 2000$ basic income (and the actor none), we could simply keep the waitress' $\$ 1000$ basic income in place and eliminiate the $\$ 1000$ that would have been allocated to the actor under the UBI. Doing so would reduce total and average welfare compared to the UBI, but it would potentially greatly reduce the real-world cost of the non-universal basic income scheme. Furthemore, it would technically represent a more effective use of money because the money that would in any case have lower utility is not allocated at all. The waitress' potential second $\$ 1000$ would still be beneficial to her, but less so than the first $\$ 1000$ she already received. Eliminating the second $\$ 1000$ altogether technically means saving $\$ 1000$ that could not under any circumstance have been as effective as the first $\$ 1000$.

However, if effectiveness is the primary goal under such a non-universal basic income scheme that is concerned with minimizing costs, we would end up in a kind of race to the bottom of ever smaller basic incomes allocated to only those in extreme distress. Since we know that additional money has the greatest impact when one has little income and wealth a priori, the most effective basic income could very well be a tiny one given to almost no one. For example, a $\$ 100$ monthly basic income would have, relatively speaking, a positive moral impact for a person with no income, no wealth, but with $\$ 50000$ of medical debt. However, even an additional $\$ 100$ given to the same person would already exhibit some diminishing marginal utility, which technically means that those additional $\$ 100$ could be used more effectively elsewhere. But if that conclusion is true, then the first $\$ 100$ that the person received are also called into question, since those $\$ 100$ could be used more effectively elsewhere as well. There might, for example, be a person with no income, no wealth and with $\$ 60000$ rather than $\$ 50000$ of medical debt. But then, there might be a person even worse off, and so forth, ad infinitum.

In order to avoid this infinite regress towards effectiveness under a costsensitive non-universal basic income, we have to add additional criteria for a minimum level of welfare that the non-universal basic income would need to create. This means that the rule of welfare-maximization effectiveness has to be supplemented with a minimum welfare guarantee in a Rawlsian [21] or Dworkian [22] sense. Even a cost-sensitive basic income has to provide the basic goods that are required to make life worth living. 


\section{Potential objections}

In this section, I discuss some of the potential objections to the argument I present above. The list of the objections I discuss here is not exhaustive, but I believe that they represent some of the major criticisms that could be leveled at my case against the UBI.

\subsection{The equality objection}

One of the factors that makes the UBI an elegant concept is the fact that every (adult) person receives the exact same amount of money, no matter what. One could make the argument that this universalist ambition of the UBI is not just a matter of elegance, but also a matter of morality. The identical treatment of every person, regardless of their socio-economic status, could be regarded as a moral goal sui generis worth pursuing more than the increase in total and average welfare. After all, we like to think of all people being equal, so is it not in one way or the other only fair to treat them all exactly the same under the umbrella of a UBI?

I see little merit in this line of thought. Under a non-universal basic income scheme that is aimed at maximizing welfare, all people actually are treated as equals and they all have the exact same right to a basic income. The only caveat is that the income they receive is contingent on their a priori material conditions, but if their a priori material conditions worsen for whatever reason, they will start receiving a basic income. There is nothing especially egalitarian about handing out the exact same basic income to all people all the time, because even those people who are well off at time $t_{1}$ (and do not receive the non-universal basic income at that time) will benefit more from the non-universal basic income than they would from a UBI $t_{2}$ if they happen to fall on hard times by $t_{2}$. Under a non-universal basic income that aims to maximize its moral impact, all people are perfectly equal and they are also better off than under a UBI.

One could further defend the equality objection by equating the UBI with something like equality of opportunity. A UBI would make sure that all people have a guaranteed minimum level of opportunity they can then use in whatever way they see fit. But all of these considerations are already part of the welfare maximization goal under non-universal basic income: Greater welfare includes more freedom to make whatever life decisions one wishes to make. The point is again that the UBI is worse at creating this equality of opportunity than a non-universal basic income adjusted for prior material conditions. The wealthy actor in our thought experiment already has all the opportunities he could wish for; an additional $\$ 1000$ UBI would change next 
to nothing for him. The waitress' opportunities, on the other hand, would greatly increase with a $\$ 1000$ monthly basic income, and an additional $\$ 1000$ would improve her outlook even more and still significantly. A non-universal basic income is more effective at achieving equality of opportunity for the same reasons it is more effective at increasing average and total welfare in the population.

\subsection{The deontological objection}

In this article, I frame the UBI as a fundamentally utilitarian project. My starting point is the observation that the moral merit of the UBI lies in its utilitarian amibition, and then I go on to argue that from the very same utilitarian perspective that is inherent to the UBI, the UBI is inadequate compared to a non-universal basic income that is adjusted for prior material conditions. But could the moral foundation of the UBI not be utilitarian but rather deontological in nature? In other words: Is the moral principle underpinning the UBI not actually the goal of maximizing welfare, but rather something like the obligation or duty to provide all people in a population with the same and unconditional quantity of a good? In such a deontological conceptualization of the UBI, the UBI can be understood as something like a basic or human right rather than a welfare-increasing tool [23]. From such a perspective, the UBI should be universal and unconditional just as other fundamental rights such as freedom and dignity and equality are. Because all humans are equal, so too should the basic income be.

Framing the UBI as a deontological project is, I believe, flawed for a number of reasons. Firstly and most importantly, it is in my view nearly impossible to justify the UBI (or any other kind of basic income) in a non-utilitarian manner because the very nature of the basic income is fundamentally instrumental - a basic income is good because it makes it possible to achieve certain moral goals. The basic income is not good in and of itself; it is just a tool to achieve other goals. The reality of the instrumental nature of the basic income can be easily demonstrated. Say, for example, that a wealthy Western country were to introduce a yearly UBI of around $\$ 1$. Such a UBI would rightly be ridiculed, because it would fail to $d o$ any good. The UBI in and of itself is irrelevant; it's the higher-order goals that the UBI allows us to achieve that matter.

Secondly, even though the UBI or any other basic income scheme can only be meaningfully justified in utilitarian terms, such schemes already contain a strong deontological compontent because they apply rule utilitarianism [24. Basic income schemes operate within a very specific set of rules that determine who receives how much income in order to increase individual 
as well as total and average welfare. This is fairly obvious, of course, but classical act utilitarianism is concerned only with single acts without any adherence to or establishment of general rules. If a basic income scheme were to operate without specific rules and allocate income strictly on a case-by-case basis, that would potentially violate deontological principles like equality ${ }^{5}$. But no reasonable basic income scheme aims to do that, including the type of non-universal basic income that I argue for in this article.

\subsection{The meritocratic objection}

Let us assume that in our thought experiment, the waitress and the actor have perfectly equal capabilities and they grew up in families that enjoyed the exact same level of material wealth. Furthermore, the waitress and the actor enjoyed perfectly equal opportunities to succeed in their respective professional life, and they have exactly the same talents and interests and preferences. The only factor that affects their current material conditions is their work ethic: The actor works harder than the waitress and he is rewarded accordingly. Given this meritocratic assumption, one could object to the argument of this article by pointing out that a non-universal basic income scheme amounts to a punishment for people who are willing to work harder. After all, our waitress could work harder and be a successful actress herself, but she chooses not to - should she be rewarded for her lacking work ethic with a $\$ 2000$ basic income whereas the actor who is actually willing to work hard is punished and receives nothing? Surely the UBI is morally preferable because it does not discriminate against hard work?

There are multiple refutations to this meritocratic objection. First, it is well known that notions of pure meritocracy have little to do with the reality of inequality (see for example [25, 26]). People's material conditions are heavily affected by chance (a person born into extreme poverty has had no say in the matter) and by dynamics of cumulative inequality (prior economic status affects chances of socio-economic mobility [27]).

Second, if one thinks that the UBI is preferable to a non-universal basic income because the latter violates meritocratic principles and discriminates against hard work, then the UBI itself should be regarded as inferior to a basic income scheme in which the allocation of basic income is positively correlated with prior income and wealth. In other words: If one seriously

\footnotetext{
${ }^{5}$ For example, it would be conceivable in theory to distribute a form of basic income only according to subjective feelings of happiness and suffering. This could mean that a person in dire material conditions who happens to have, by pure chance, favorable traits such as high resilience and overall relatively good physical and mental health could receive less income than a millionaire who, by pure bad luck, happens to be suffering from depression.
} 
believes in the meritocratic argument, then a basic income should not only not discriminate against hard work, but actually reward it. The actor should receive $\$ 2000$ and the waitress should receive nothing. But such a view is both divorced from empirical reality and from common moral considerations.

\subsection{The stigma objection}

An ongoing problem of traditional welfare programs is that they carry a heavy stigma. Welfare stigma means that potential recipients are less likely to accept welfare when they need it, and that the well-being of recipients is lowered because of, among other factors, feelings of shame and inadequacy $[28,29,30$. The persistence of welfare stigma is at least partially connected to neoliberal efforts of framing welfare as failures of personal responsibility rather than systemic failures and collective moral obligations [31, 32.

The UBI would, in essence, completely circumvent stigma: Since each person would receive the exact same basic income, there would simply be no room for any kind of stigma - everyone is treated universally the same. In contrast, a large proportion of non-universal basic income would likely be allocated to the low-income, low-wealth, working-class stratum of the people who are eligible for traditional welfare programs, meaning that stigma could persist under such a scheme. This is, I believe, a strong practical argument against a non-universal basic income as opposed to a UBI. With a UBI, the problem of stigmatization is solved by design, whereas it needs to be addressed in some manner under a non-universal basic income scheme.

One way of reducing stigma under a non-universal basic income scheme would be to automate and simplify the allocation of the basic income as much as possible. This would require creating a system in which income and wealth are recorded in regular intervals, for example each month, so that a basic income can be allocated dynamically and automatically. The need for such a system, however, leads us to a next potential objection to non-universal basic income: The question of additional bureaucracy.

\subsection{The bureaucracy objection}

Under a UBI, relatively little additional governmental bureaucracy would need to be put into place. Managing the UBI would certainly require people and work, but the allocation of the UBI would be relatively simple: All eligible people receive the exact same basic income. A non-universal basic income, on the other hand, would by design have to be more bureaucratically complex. Since such a scheme would be contingent on current levels of income and wealth, a system would need to be created that is capable of 
recording such data in a dynamic manner (for example, on a monthly basis). Creating such a system would almost certainly amount to a significantly greater bureaucratic effort than creating a "lean" bureaucratic system for a UBI.

The greater buraucratic challenge of non-universal basic income could, however, become a medium- and long-term net benefit from a bureaucratic perspective. Creating a system that records income and wealth on a monthly basis would do away with traditional yearly tax declarations that are themselves a large bureaucratic challenge, and it would in all likelihood also simplify tax declarations for individuals by, for example, implementing means of automatically recording income. Implementing a UBI, on the other hand, would do nothing to simplify or automate the tax system because it is disconnected from it.

\subsection{The willingness to pay objection}

If a basic income scheme were to be implemented, it would probably require additional funding beyond what would become available through reducing or eliminating existing welfare programs. One, and perhaps the most likely vector of securing the necessary funding would be through greater progressive taxation of income and potentially (or necessarily) wealth. Neoclassical economic considerations tell us that wealthier people's willingness to pay for a basic income scheme should at least to some degree be affected by the benefits from such a program for themselves. If they themselves also receive a basic income under, for example, a UBI, it stands to reason that the benefits of the basic income scheme would be more salient and tangible to them and that, by extension, their willingness to pay for the program might also be greater because they experience the benefits more directly.

This objection is mostly an empirical question and it should be further investigated, primarily because willingness to pay might affect the real-world chances of implementing a non-universal basic income as opposed to a UBI. It has been observed many times that general willingness to pay deviates from pure rational choice models and is instead heavily affected by irrational, emotional aspects [33, 34, 35]. Whether receiving a basic income affects one's willingness to pay for a basic income is therefore not self-evident. There are at least two empirical questions that warrant closer scrutiny. First, is willingness to pay for a basic income scheme contingent on receiving a basic income (either a uniform one or one that is universal but still varies depending on income and wealth)? And second, can willingness to pay for a basic income scheme be increased through non-monetary, psychological measures (such as framing of the issue, increasing emotional salience, etc.)? 


\section{Conclusion}

The UBI is morally desirable because it increases total and average welfare. In other words, the UBI is good because it clearly improves peoples' lives. However, as I tried to argue in this article, this moral goal of the UBI can be achieved more effectively through a non-universal basic income that is adjusted for prior material conditions and the decreasing marginal utility of money: Allocating a basic income based on individuals' prior income and wealth makes it possible to significantly increase the overall positive moral impact of the money that is being distributed under a basic income scheme. In theory, such a non-universal basic income categorically outperforms the UBI in terms of the maximization of average and total welfare in the population. The UBI is morally good, but a non-universal basic income is better.

Does this utilitarian case against the UBI mean that in the real world, a form of non-universal basic income adjusted for prior material conditions should be pursued rather than the UBI? I believe so, but there are at least two important objections to this proposition. First, a UBI would entirely avoid the problems associated with welfare stigma, whereas a non-universal basic income might suffer from them. Second, the public willingness to pay for a non-universal basic income might be lower than their willingness to pay for a UBI. However, I see neither of these objections to a non-universal basic income as insurmountable. They are problems that can be solved: A nonuniversal basic income can be designed in such a way as to minimize stigma, and willingness to pay might be increased with psychologically adequate messaging (If willingness to pay is even a relevant empirical parameter at all, that is.).

The utilitarian argument against the UBI might at first glance seem like a defence of the negative income tax (NIT). It is not. Even though the NIT does partially take into account the principle of diminishing marginal utility by making the basic income conditional on one's "regular" income, the NIT is actually crassly inferior to the UBI and potentially even to the status quo of no basic income at all. The NIT disregards wealth and the welfare derived from wealth, which would inevitably lead to morally absurd constellations if a NIT were to be implemented (A millionaire who decided to travel the world for a year and to not work during that time would be considered worse off than a minimum wage worker living paycheck to paycheck in that same year.).

What is the key takeaway of this article? The main, and in my view only rational justification for the UBI is its positive moral impact: A UBI would, without a doubt, increase total and average welfare in a population. But if we sincerely care about the moral goal and the moral impact of the 
UBI, then we should be open to non-universal forms of basic income that are better than the UBI at achieving UBI's goal. Defining in greater detail what a non-universal basic income that incorporates the principle of diminishing marginal utility of money and the effect of prior material conditions might look like in practice is part of the conceptual and empirical work that lies ahead. 


\section{References}

[1] Philippe Van Parijs. Why Surfers Should be Fed: The Liberal Case for an Unconditional Basic Income. Philosophy $\& 5$ Public Affairs, 20(2):101131, 1991.

[2] Philippe Van Parijs. Basic Income: A Simple and Powerful Idea for the Twenty-First Century. Politics \& Society, 32(1):7-39, March 2004.

[3] Philippe Van Parijs. Real Freedom for All: What. Oxford University Press, USA, Oxford, January 1998.

[4] Juliana Uhuru Bidadanure. The Political Theory of Universal Basic Income. Annual Review of Political Science, 22(1):481-501, 2019.

[5] Louise Haagh. The Case for Universal Basic Income. Polity, Medford, MA, 1 edition edition, July 2019.

[6] Arne Ruckert, Chau Huynh, and Ronald Labonté. Reducing health inequities: is universal basic income the way forward? Journal of Public Health, 40(1):3-7, March 2018.

[7] Marcia Gibson, Wendy Hearty, and Peter Craig. Potential effects of universal basic income: a scoping review of evidence on impacts and study characteristics. The Lancet, 392:S36, November 2018.

[8] Hilary Hoynes and Jesse Rothstein. Universal Basic Income in the United States and Advanced Countries. Annual Review of Economics, 11(1):929-958, 2019.

[9] Abhijit Banerjee, Paul Niehaus, and Tavneet Suri. Universal Basic Income in the Developing World. Annual Review of Economics, 11(1):959983, 2019 .

[10] R. I. SIKORA. Utilitarianism: the Classical Principle and the Average Principle. Canadian Journal of Philosophy, 5(3):409-419, January 1975.

[11] Derek Parfit. Overpopulation and the Quality of Life. In Torbjörn Tännsjö and Jesper Ryberg, editors, The Repugnant Conclusion, volume 15, pages 7-22. Springer Netherlands, Dordrecht, 2004.

[12] James Woodward. The Non-Identity Problem. Ethics, 96(4):804-831, July 1986. 
[13] Philip Pettit. A Republican Right to Basic Income? Basic Income Studies, 2(2), January 2008.

[14] Karl R. Popper, Alan Ryan, and E. H. Gombrich. The Open Society and Its Enemies: New One-Volume Edition. Princeton University Press, Princeton, new edition edition, April 2013.

[15] Alfred Marshall. Principles of Economics. Palgrave Classics in Economics. Palgrave Macmillan UK, 2013.

[16] R. Layard, G. Mayraz, and S. Nickell. The marginal utility of income. Journal of Public Economics, 92(8):1846-1857, August 2008.

[17] Ed Diener, Weiting Ng, James Harter, and Raksha Arora. Wealth and happiness across the world: Material prosperity predicts life evaluation, whereas psychosocial prosperity predicts positive feeling. Journal of Personality and Social Psychology, 99(1):52-61, 2010.

[18] Davide Tondani. Universal Basic Income and Negative Income Tax: Two different ways of thinking redistribution. The Journal of SocioEconomics, 38(2):246-255, March 2009.

[19] James Tobin, Joseph A. Pechman, and Peter M. Mieszkowski. Is a Negative Income Tax Practical? The Yale Law Journal, 77(1):1-27, 1967.

[20] Facundo Alvaredo, Lucas Chancel, Thomas Piketty, Emmanuel Saez, and Gabriel Zucman. World Inequality Report 2018. Harvard University Press, 2018.

[21] John Rawls. Political Liberalism. Columbia University Press, New York, expanded edition edition, March 2005.

[22] Ronald Dworkin. What is Equality? Part 2: Equality of Resources. Philosophy 85 Public Affairs, 10(4):283-345, 1981.

[23] Daniel J. Hemel. Basic Income as a Human Right? In Tax, Inequality, and Human Rights, pages 541-552. Oxford University Press, July 2019.

[24] Brad Hooker. Rule Consequentialism. In Edward N. Zalta, editor, The Stanford Encyclopedia of Philosophy. Metaphysics Research Lab, Stanford University, winter 2016 edition, 2016.

[25] Jo Littler. Meritocracy as Plutocracy: The Marketising of 'Equality' Under Neoliberalism. New Formations, 80(80):52-72, November 2013. 
[26] Robert H. Frank. Success and Luck: Good Fortune and the Myth of Meritocracy. Princeton University Press, April 2016.

[27] Dan Andrews and Andrew Leigh. More inequality, less social mobility. Applied Economics Letters, 16(15):1489-1492, October 2009.

[28] Patrick M. Horan and Patricia Lee Austin. The Social Bases of Welfare Stigma. Social Problems, 21(5):648-657, June 1974.

[29] Robin Rogers-Dillon. The dynamics of welfare stigma. Qualitative Sociology, 18(4):439, December 1995.

[30] Jennifer Stuber and Mark Schlesinger. Sources of stigma for meanstested government programs. Social Science $\mathscr{E}$ Medicine, 63(4):933-945, August 2006.

[31] Shawn A. Cassiman. Resisting the Neo-liberal Poverty Discourse: On Constructing Deadbeat Dads and Welfare Queens. Sociology Compass, 2(5):1690-1700, 2008.

[32] Michele Estrin Gilman. The Return of the Welfare Queen. American University Journal of Gender, Social Policy \&s the Law, 22:247, 2013.

[33] Daniel Kahneman, Ilana Ritov, Karen E. Jacowitz, and Paul Grant. Stated Willingness to Pay for Public Goods: A Psychological Perspective. Psychological Science, 4(5):310-315, September 1993. Publisher: SAGE Publications Inc.

[34] Cass R. Sunstein. Willingness to Pay vs. Welfare. Harvard Law $\&$ Policy Review, 1:303, 2007.

[35] Ulf Liebe, Peter Preisendörfer, and Jürgen Meyerhoff. To Pay or Not to Pay: Competing Theories to Explain Individuals' Willingness to Pay for Public Environmental Goods. Environment and Behavior, 43(1):106130, January 2011. 